\title{
AURÉLIA CERVONI, Pétrus Borel
}

\section{Ida Merello}

\section{OpenEdition \\ Journals}

\section{Édition électronique}

URL : https://journals.openedition.org/studifrancesi/45330

DOI : 10.4000/studifrancesi.45330

ISSN : 2421-5856

\section{Éditeur}

Rosenberg \& Sellier

\section{Édition imprimée}

Date de publication : 1 août 2021

Pagination : 393-394

ISSN : 0039-2944

\section{Référence électronique}

Ida Merello, « AurélIA cervoni, Pétrus Borel », Studi Francesi [En ligne], 194 (LXV | II) | 2021, mis en ligne le 01 septembre 2021, consulté le 14 octobre 2022. URL : http://journals.openedition.org/studifrancesi/ 45330 ; DOI : https://doi.org/10.4000/studifrancesi.45330

Ce document a été généré automatiquement le 14 octobre 2022.

\section{(c)}

Creative Commons - Attribution - Pas d'Utilisation Commerciale - Pas de Modification 4.0 International - CC BY-NC-ND 4.0

https://creativecommons.org/licenses/by-nc-nd/4.0/ 


\title{
AURÉLIA CERVONI, Pétrus Borel
}

\author{
Ida Merello
}

\section{RÉFÉRENCE}

AURÉLIA CERVONI, Pétrus Borel, Paris, Presses Universitaires de la Sorbonne, 2020, «Mémoires de la critique», 590 pp.

Grâce à Aurélia CERVONI, et à ses longues études sur Pétrus Borel, l'auteur est finalement entré dans la collection des «Mémoires de la critique», où sont regroupés les articles qui le concernent parus entre 1831 et 1915. Dans son préambule Aurélia Cervoni montre que les premiers recenseurs s'étonnaient surtout du goût de la provocation et de la bizarrerie de l'écrivain. Suivant le parcours de sa renommée, l'A. met en évidence qu'entre 1840 et 1860 on ne peut glaner que très peu d'articles, surtout anecdotiques; tandis que souvent Borel est utilisé pour persifler quelqu'un comme deuxième terme de comparaison: le lycanthrope fait son devoir. Sa mort aussi, en 1859, était l'objet d'hypothèses à la limite du grotesque: il pouvait être mort de faim ou d'insolation, selon les uns ou les autres. On se souvenait surtout de son humour macabre, qui l'amenait à se proclamer anthropophage et buveur de sang humain. Même son costume faisait l'objet de représentations moqueuses qui arrivaient jusqu'à la dérision. Tous ces éléments entraînaient à une considération négative. Catulle Mendès reprend cette attitude dérisoire dans son Mouvement de la poésie de 1903. Pourtant, comme nous en avertit Aurélia Cervoni, quelque chose avait déjà commencé à changer à partir des années 1860: les œuvres de Borel sont à nouveau éditées, mais cette fois dans des collections précieuses et elles deviennent patrimoine des bibliophiles, tandis que Baudelaire et Flaubert inaugurent une nouvelle fortune critique de l'auteur, considéré comme un exemple de romantisme noir. Verlaine reconnaît l'influence de Borel dans la deuxième moitié du XIX siècle; le mouvement symboliste commence à réévaluer la place de celui-ci à l'intérieur du romantisme. L'A. montre que l'appréciation de Breton se situe dans le prolongement du sillage symboliste. Breton définit Pétrus Borel comme le 
bouc émissaire de romantisme, et Tzara apprécie aussi bien la marginalité de Borel que son caractère éversif.

Le travail de Mme Cervoni se qualifie par la minutie de la recherche des documents, qui commence par les tous premiers articles publiés du vivant de l'auteur, et qui sont souvent anonymes. L'ouvrage est divisé en trois parties: dans la première sont recueillis les textes de novembre 1831 à 1915 . On voit que les critiques sont intéressés par les Rhapsodies et par Champavert. Très tôt on commence à parler de la lycanthropie de Borel: orientation que suit un article anonyme, reconnu pourtant comme de William Thackeray. Mme Putiphar est aussi l'objet d'intérêt critique et artistique; Janin lui consacre un article dans le "Journal des débats". On voit que peu à peu tout au long du siècle Borel est moins l'objet d'une attention précise portée sur ses œuvres, mais plutôt il est considéré comme un élément d'importance à l'intérieur du romantisme: les titres des articles qui lui sont consacrés concernent justement cette nouvelle attitude. L'ensemble des articles recueilli par Aurélia Cervoni se termine par un article d'Arthur Symons publié à New York en 1915. Les articles parus en anglais sont présentés dans la langue originale et aussi bien dans la traduction française. Dans la deuxième partie de l'ouvrage, Mme Cervoni recueille les notices biographiques de tous les auteurs qui sont entrés en contact avec Pétrus Borel et qui ont parlé de lui dans leurs écrits. Il s'agit d'un travail de grande érudition, très utile pour tout chercheur qui ait besoin de définir avec précision les rapports de la deuxième génération romantique. La troisième partie est constituée par un ensemble de points de repère bibliographiques: on y trouve la liste des œuvres publiées du vivant de Pétrus Borel, les œuvres posthumes et un grand apparat d'index de nom. 